\title{
ВИКОРИСТАННЯ ІНДУСТРІАЛЬНИХ ОЦІНОК ДЛЯ ВИЗНАЧЕННЯ ЯКОСТІ НАДАННЯ МЕДИЧНОЇ ДОПОМОГИ В УМОВАХ ДЕРЖАВНО-ПРИВАТНОГО ПАРTHEPCTBA
}

\author{
П. П. Ганинець, Н. О. Сінєнко \\ Національна медична академія післядипломної освіти імені П. Л. Шупика
}

\begin{abstract}
Розглянуто питання застосування деяких індустріальних оцінок для кількісного визначення якості надання допомоги пацієнтам на реабілітаційному етапі лікування. Водночас проводили зіставлення цих оцінок у структурах об'єктів державного і приватного секторів. Підкреслюється, що якщо фрінансові та адміністративні питання подібної взаємодії певною мірою вивчені, то кількісна оцінка якості надання медичної допомоги в умовах державно-приватного партнерства (ДПП) до сьогодні викликає питання. Вони особливо очевидні в аналізі ефективності співпраці під час реабілітації пацієнтів. Розглянуто аспекти використання застосування теорії ефективності Парето і фрункції втрат Тагучі. Обговорено теоретичні підходи до застосування науково-технологічного інструментарію реалізації ДПП у медичних установах, зокрема в реабілітаційному центрі. В їхню основу закладено інструментальні підходи оцінки якості медичної допомоги. Показано, що застосування методик оцінки Парето і фрункції втрат Тагучі дозволяє кількісно охарактеризувати поліпшення якості надання медичної допомоги за ДПП. Показано також, що показники клінічної роботи та середні результати реабілітації близькі. Однак, повторюваність результатів за ДПП була значно вищою, а число лікарських помилок зменшилося на 42\% $3 \%$. Інтегральна оцінка за методами Парето і Тагучі виявилася зміщеною в бік ДПП. Величина відстані ВА становила 1,7 умовних одиниць, що можна вважати кількісним доказом ефективності нового фрормату діяльності санаторію.
\end{abstract}

Ключові слова: якість медичної допомоги, кількісні оцінки медичної допомоги, індустріальні оцінки якості медичної допомоги, ризик несприятливого результату, державно-приватне партнерство, теорія ефективності Парето, фрункція втрат Тагучі, ризик-менеджмент у практиці медичної установи.

\section{THE USE OF INDUSTRIAL ASSESSMENTS TO DETERMINE THE QUALITY OF CARE IN PUBLIC-PRIVATE PARTNERSHIP}

\section{P. P. Hanynets, N. O. Sinyenko \\ Shupyk National Medical Academy of Postgraduate Education}

\begin{abstract}
Background. The issues of application of some industrial assessments for the quantitative determination of the quality of care for patients at the rehabilitation stage of treatment are considered.

Results. At the same time, these assessments were compared in the structures of public and private sectors. It is emphasized that if the financial and administrative issues of such interaction have been studied to a certain extent, then a quantitative assessment of the quality of medical care in a public-private partnership (PPP) still raises questions. They are especially evident in the analysis of the effectiveness of cooperation in the rehabilitation of patients. The aspects of using the Pareto efficiency theory application and the Taguchi loss function are considered. The theoretical approaches to the use of scientific and technological tools for the implementation of PPPs in medical institutions, in particular in a rehabilitation center, were discussed. They are based on instrumental approaches to assessing the quality of medical care. It is shown that the use of Pareto assessment methods and the Taguchi loss function allows us to quantitatively characterize the improvement in the quality of care provided for PPPs. It is also shown that the indicators of clinical work and the average results of rehabilitation are close. However, the repeatability of results in PPP was significantly higher, and the number of medical errors decreased by $42 \% \pm 3 \%$. The integral evaluation by the Pareto and Taguchi methods turned out to be shifted towards PPP. The distance VA was 1.7 conventional units, which can be considered a quantitative proof of the effectiveness of the new format of the sanatorium's activities.
\end{abstract}

Key words: quality of medical care, quantitative assessments of medical care, industrial assessments of the quality of medical care, risk of adverse outcome, public-private partnership, Pareto efficiency theory, Taguchi loss function, risk management in the practice of a medical institution. 


\title{
ИСПОЛЬЗОВАНИЕ ИНДУСТРИАЛЬНЫХ ОЦЕНОК ДЛЯ ОПРЕДЕЛЕНИЯ КАЧЕСТВА ОКАЗАНИЯ МЕДИЦИНСКОЙ ПОМОЩИ В УСЛОВИЯХ ГОСУДАРСТВЕННО-ЧАСТНОГО ПАРТНЕРСТВА
}

\author{
П. П. Ганынец, Н. А. Синенко \\ Национальная медицинская академия последипломного образования имени П. Л. Шупика
}

\begin{abstract}
Рассмотрены вопросы применения некоторых индустриальных оценок для количественного определения качества оказания помощи пациентам на реабилитационном этапе лечения. Одновременно проводилось сопоставление этих оценок в структурах объектов государственного и приватного секторов. Подчеркивается, что если финансовые и административные вопросы подобного взаимодействия в известной степени изучены, то количественная оценка качества оказания медицинской помощи в условиях государственно-частного партнерства (ГЧП) до настоящего времени вызывает вопросы. Они особенно очевидны в анализе эфреективности сотрудничества при реабилитации больных. Рассмотрены аспекты использования приложения теории эффективности Парето и фрункции потерь Тагучи. Обсуждены теоретические подходы к применению научно-технологического инструментария реализации ГЧП в медицинских учреждениях, в частности в реабилитационном центре. В их основу заложены инструментальные подходы оценки качества медицинской помощи. Показано, что применение методик оценки Парето и фрункции потерь Тагучи позволяет количественно охарактеризовать улучшение качества оказания медицинской помощи при ГЧП. Показано также, что показатели клинической работы и средние результаты реабилитации близки. Однако повторяемость результатов при ГЧП была значительно выше, а число врачебных ошибок уменьшилось на 42\% $\%$ \%. Интегральная оценка по методам Парето и Тагучи оказалась смещенной в сторону ГЧП. Величина расстояния ВА составила 1,7 условных единиц, что можно считать количественным доказательством эфрфективности нового формата деятельности санатория.
\end{abstract}

Ключевые слова: качество медицинской помощи, количественные оценки медицинской помощи, индустриальные оценки качества медицинской помощи, риск неблагоприятного исхода, государственно-частное партнерство, теория эффрективности Парето, фрункция потерь Тагучи, риск-менеджмент в практике медицинского учреждения.

Вступ. Державно-приватне партнерство (ДПП) - ефективна формула підвищення ефективності народного господарства. Складнощі організації дієвого ДПП здебільшого пов'язані з необхідністю створення гармонізованого інституційного та організаційного альянсу державної влади та бізнесу. Такий альянс повинен забезпечити визначення, розробку та реалізацію масштабних суспільно значущих проектів, здатних охопити широкий спектр напрямків діяльності в різних секторах економіки та діяти в рамках як держави, так і окремих територій. Активний розвиток різних форм ДПП відбувається практично в усіх регіонах світу, насамперед в охороні здоров'я країн з різною економікою. Досвід його використання дозволяе трактувати цю форму взаємин як характерну рису сучасної змішаної економіки. Слід враховувати, що ДПП у сфері охорони здоров’я, на відміну від традиційних адміністративних відносин, створює особливі моделі відносин власності, фінансування та методів управління [1-4].

Слід підкреслити, що хоча сьогодні в Україні створена нормативно-правова база, яка забезпечує можливість розробки державної концепції ДПП в охороні здоров'я, проте критерії ефективності якості медичної допомоги досі не затверджені.
Водночас саме такі критерії мають вирішальне значення для інтегральної оцінки корисності ДПП.

Мета дослідження: оцінити ефективність використання індустріальних критеріїв якості надання медичної допомоги пацієнтам в умовах державноприватного партнерства.

Матеріал і методи дослідження. Вивчено результати реабілітації 300 пацієнтів на гастроентерологічну патологію, які проходили оздоровлення в санаторії «Квітка полонини» ТОВ «Сузір’я». 160 пацієнтів проходили реабілітацію в приватній частині санаторію, 140 - у державній. Дослідження проводили в однакових умовах одні й ті самі медичні працівники відповідно до державних стандартів. Так само здійснювали й застосування лікувальних вод («Лужанська-4», «Лужанська-7», «Поляна Квасова») та лікарських засобів. Проте умови проживання в приватній частині санаторію були кращими, пацієнти могли користуватися розширеними діагностичними та лікувальними можливостями.

Для оцінювання та зіставлення ефективності реабілітації запропоновано спеціальну методику.

Результати та їх обговорення. Принциповим у процесі розвитку ДПП є комплекс питань, пов'язаних із перерозподілом прав власності, оскільки партнерство інституційне перероджує 
відносини в сфері охорони здоров’я, що традиційно належали до державного ведення. На практиці це передбачає розробку механізмів передачі приватним партнерам певної частини функцій з матеріально-технічного обслуговування лікувально-профілактичних установ різних рівнів (як державної, так і комунальної власності), зокрема йдеться про діагностичні дослідження, організацію харчування пацієнтів, дезінфекцію, транспортні, побутові послуги, зв’язок тощо. У найпростіших випадках (організація харчування, лабораторні дослідження) це дійсно працює. У складніших ситуаціях оцінка корисності об’єднання може виявитися дискусійною. Типовим прикладом є створення паралельних структур діагностики та лікування пацієнтів, де логіка користі не дає однозначної відповіді.

Вважають, що ефективним слід визнати процедуру еталонного порівняння (процедура бенчмаркінгу). Пропонується порівняння якості надання медичної допомоги в своєму ЛПУ з присутньою на ринку якістю, насамперед такою, що пропонують конкуренти. На основі цієї інформації рекомендується приймати рішення, що стосуються різних аспектів діяльності санаторію, зокрема щодо доцільності використання різних методик і щодо можливості поліпшення технологій реабілітації. Але насправді це не так. Виняткова багатофакторність, обумовлена принциповою невідповідністю умов реабілітації в різних санаторних установах, несумісність стану пацієнтів роблять завдання еталонного зіставлення мало здійсненним.

Під якістю медичної допомоги розуміли сукупність характеристик, що підтверджують відповідність наданої медичної допомоги наявним потребам пацієнта (населення), його очікуванням, сучасному рівню медичної науки і технології, а під послідовністю медичної допомоги - ступінь координації практикуючих фахівців, організацій протягом усього періоду надання медичної допомоги пацієнту (медичного втручання). Нарешті, під координацією медичної допомоги розуміють таку медичну допомогу, при якій ймовірність несприятливого результату (або небажаних ускладнень) принаймні не підвищується.

При оцінюванні якості медичної допомоги враховували кількість медичних помилок. При цьому вважали, що лікарська помилка - неправомірна дія чи бездіяльність лікаря, якщо це ускладнило або могло ускладнити виконання медичних технологій, сприяло або могло сприяти збільшенню або стабілізації ризику прогресування наявного у пацієнта захворювання, виникнення нового патологічного процесу, неоптимальному використанню ресурсів медицини. Значимість лікарської помилки також оцінювали за величиною ймовірності несприятливого результату та ступеня незадоволеності пацієнта.

Суттєве значення в оцінці результатів надання медичної допомоги слід приписати також ключовими характеристиками, що визначають задоволеність пацієнта (комфорт, турбота, впевненість, зручність, спілкування і вартість). Інтегральна характеристика суб'єктивних відчуттів хворого дозволила оцінити додаткові конкретні показники реабілітаційного процесу [5].

Отже, при оцінюванні якості медичної допомоги враховували всі рекомендації Всесвітньої організації охорони здоров'я. А саме такі компоненти якості медичної допомоги, як: 1) професійні функції (або виконання лікувально-діагностичного процесу), кваліфікація лікаря; 2) ризик для пацієнта внаслідок медичного втручання; 3) оптимальність використання ресурсів; 4) задоволеність пацієнта наданою медичною допомогою [6].

Однак можна виділити безліч різноманітних ситуацій, з якими ми стикаємося щодня, коли визначити якість надання медичної допомоги досить складно. У ряді випадків про обсяг і відповідність виконаних діагностичних і лікувальних дій поінформована лише одна сторона — медичні працівники. Інакше кажучи, пацієнт не знає, що саме він отримав, а якість медичної допомоги з'ясовується значно пізніше. Потенційні пацієнти, а іноді і потенційні експертні групи часто приховують справжні цілі своєї поведінки і використовують практично всі способи для отримання односторонніх вигод. Пацієнти під час надання їм амбулаторної медичної допомоги часто не надають усієї інформації лікарю, що важлива для встановлення коректного діагнозу. Ця ситуація, так звана інформаційна асиметрія, відіграє серйозну роль в оцінці корисності, оптимальності медичної допомоги, оцінці переваг при виборі лікувальної стратегії.

Відповідно, хоча вимоги про повноту, валідність та точність медичної інформації постулюються протягом понад двох останніх століть, насправді вони повністю не виконуються.

Відповідно, в концептуальній стратегії оцінки якості медичної допомоги важливо оцінювати не тільки оптимальність (корисність), але і функцію втрат. 
Для інтегральної індустріальної оцінки якості медичної допомоги нами обрані показники ефективності Парето (W. F. Pareto) і функція втрат Тагучі (G. Taguchi).

Однак, отримана оцінка занадто загальна. Деталізація підходу пов'язана із застосуванням індустріальних показників якості медичної допомоги.

Застосовували критеріальний підхід, пов'язаний з логікою визначення оптимальності за Парето [7-9]. Оптимальним вважали такий стан системи, за якого значення кожного окремого критерію, що описує стан хворого, не може бути покращене з погіршенням значення інших показників. Безліч станів системи, оптимальних за Парето, називали множиною оптимальних альтернатив. Ситуація, коли досягнута ефективність за Парето, - це ситуація, коли всі підходи до досягнення більш сприятливого результату є вичерпаними.

Інакше кажучи, економіка установи є ефективною, якщо проводиться максимально можливий обсяг необхідних медичних послуг за наявних обмежених ресурсів.

При оцінці якості медичних послуг окремо розглядали дві характеристики якості: якість виконання і якість відповідності.

При цьому під якістю виконання розуміли характеристику, яка відображатиме ступінь надання медичних послуг, що фактично задовольняє потреби клієнтів.

Зі свого боку, під якістю відповідності йшлося про кількісні показники відповідності медичної допомоги або послуг відповідним стандартами або протоколами. Використання логіки якості відповідності вимагало застосування класифікатора належної і неналежної якості медичної допомоги. У першому випадку йшлося про те, що надана медична допомога відповідає сучасним уявленням про іï необхідний рівень і обсяг при даному виді патології з урахуванням індивідуальних особливостей хворого і можливостей конкретного медичного закладу.

В іншому випадку (неналежна якість медичної допомоги) оцінка наданої медичної допомоги передбачала ії̈ невідповідність загальноприйнятим сучасним уявленням про іiї необхідний рівень і обсяг при даному виді патології.

Таким чином, забезпечували звуження множини прийнятних рішень до множини ефективних рішень. Воно може бути частково забезпечене на основі аналізу переваг. Будемо вважати рішення звичайно ефективним, якщо не існує кращого лікувального підходу. Якщо необхідно визначити ефективність реабілітації для групи пацієнтів, також користувалися іншим правилом Парето, вважаючи, що стан А краще за стан G, якщо хоча б для одного індивіда стан А приносить більший рівень корисності, ніж стан $\mathrm{G}$, не знижуючи рівень корисності в жодного з інших індивідів.

Багатокритерійна оцінка реабілітації для конкретного пацієнта може бути виконана також на основі відомого правила вибору за Парето: кращим вважають такий варіант проведення реабілітації, для якого не існує іншого варіанту краще даного хоча б за одним показником і не гірше за нього за всіма іншим.

Відповідно, попередньо здійснювали вибір кращої альтернативи $з$ погляду на досягнення поставлених цілей, витрат ресурсів, відповідності конкретним умовам реалізації альтернатив.

При виборі рішення про корисність (доцільність) одного з методів відновлення працездатності у пацієнта, наприклад після інсульту або інших досить складних клінічних випадків, на основі запропонованих кількісних розрахунків часто було важко виробити однозначні рекомендації про перевагу однієї альтернативи над всіма іншими. Тому виділяли групи бажаних (ефективних) альтернатив, також отриманих на основі підходів оптимізації за Парето.

Оцінку якості діагностичного та лікувального процесів отримували за допомогою інструментарію Тагучі, що, як відомо, зводиться до таких постулатів: а) зниження витрат без погіршення якості неможливо; б) підвищення якості, не збільшуючи витрат, також неможливо; в) зниження варіабельності показників функціонування санаторію сприяє підвищенню якості та ефективності [10, 11].

В основі методу Тагучі лежить квадратична функція втрат. Значення показника якості відкладається на горизонтальній осі, а вертикальна вісь показує величину «втрат» чи «шкоди». Ці втрати приймаються рівними нулю, коли характеристика якості досягає свого номінального значення.

Загальний алгоритм проілюстровано на рис. 1.

Зрозуміло, що споживачі послуг (пацієнти, хвоpi) хочуть, щоб якісний рівень медичної допомоги перебував у точці C, оскільки вони намагаються отримати максимальний ефект оздоровлення від зусиль і вкладених коштів або отримати найкращий результат за найбільш низьку плату. Однак з погляду на постачальників послуги точка С більше 


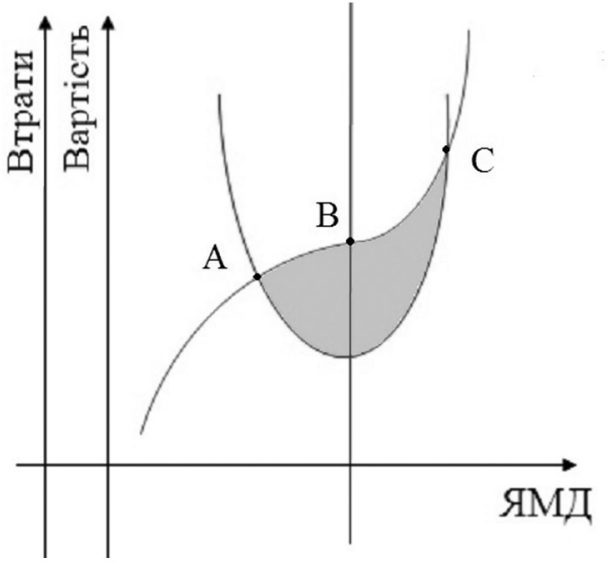

Рис. 1. Алгоритм визначення якості медичної допомоги

відповідає оптимальної якості, оскільки вона відображає найбільш економічне використання наявних ресурсів і забезпечує досить високу якість надання медичної допомоги. Власне кажучи, інтервал $\{\mathrm{C}, \mathrm{A}\}$ може бути кількісною оцінкою роботи лікувального закладу. Насправді за якісної роботи медичного закладу ми отримуємо точку В, і відстань ВА $є$ відображенням зусиль колективу медпрацівників щодо підвищення якості медичної допомоги.

Здійснювали порівняння показників функціонування санаторію до і після створення комплексу на основі ДПП як щодо клінічної роботи, інфраструктури, людських ресурсів, так і конкретних результатів.

Показники клінічної роботи та середні результати реабілітації були близькі, але в усіх випадках, що вимагають пильної уваги і використання дорогих діагностичних і лікувальних технологій за ДПП. Важливо відзначити, що і повторюваність результатів була значно вищою. Число лікарських помилок зменшилося на $42 \% \pm 3 \%$. Інтегральна оцінка за методами Парето і Тагучі виявилася зміщеною в бік ДПП. Величина відстані ВА становила 1,7 умовних одиниць, що можна вважати кількісним доказом ефективності нового формату діяльності санаторію.

Таким чином, з погляду на якість надання медичних послуг згадані результати забезпечують обгрунтування застосування технології ДПП. Інакше кажучи, хоча якість реабілітаційної допомоги певною мірою залежить від форми власності санаторію, однак споживачі можуть вибирати комбінацію і кількість послуг, які вони купують. Роль управління лікувальним закладом полягає у визначенні та підтримці прав відпочиваючих у реабілітаційному закладі, а також щоб виступати арбітром у ситуаціях з конфліктом інтересів. Насправді, однак, потреба подібного арбітражу вкрай рідкісна. Більш істотну роль можуть відігравати різні додаткові фактори і обмеження. Ці обмеження можуть бути культурними, соціальними, психологічними або технічними [12].

\section{Висновки.}

1. Представлено теоретичні підходи до застосування науково-технологічного інструментарію реалізації ДПП у медичних установах, зокрема в реабілітаційному центрі. До їхньої основи закладено інструментальні підходи оцінювання якості медичної допомоги.

2. Застосування методик оцінки Парето і функції втрат Тагучі дозволяє кількісно охарактеризувати поліпшення якості надання медичної допомоги за ДПП.

3. Показники клінічної роботи та середні результати реабілітації близькі. Однак, повторюваність результатів за ДПП була значно вищою, а число лікарських помилок зменшилось на $42 \% \pm 3 \%$. Інтегральна оцінка за методами Парето та Тагучі виявилася зміщеною в бік ДПП. Величина відстані ВА становила 1,7 умовних одиниць, що можна вважати кількісним доказом ефективності нового формату діяльності санаторію.

\section{Література.}

1. Saragiotis P, editor. Public-private partnerships in infrastructure days 2008 [Internet]. Proceedings of the 3rd «Public-Private Partnerships in Infrastructure (PPPI) days»; 2008 Dec 15-18; Washington, D.C. Washington, D.C.: The International Bank for Reconstruction and Development/The World Bank; 2009 [cited 2018 Oct 13]. 124 p. Available from: http://documents. worldbank.org/curated/en/301771468337169167/ Public-private-partnerships-in-infrastructure-days-2008.

2. Harding A, Preker A, editors, Private participation in health services. Health, nutrition and population [Internet]. Washington, DC: The World Bank; 2003 [cited 2018 Oct 13]. Taylor R J, Contracting for health services; p. 195-204. Available from: http://documents. worldbank.org/curated/en/ 665011468741360137/ Private-participation-in-health-services.

3. Delmon J J, Understanding options for public-private partnerships in infrastructure: sorting out the forest from the trees: BOT, DBFO, DCMF, concession, lease... [Internet]. Policy Research working paper; No. WPS 5173. Washington, DC: The World Bank; 2010 Jan [cited 2018 Oct 13]. 75 p. Available from: http://documents. worldbank.org/curated/en/999661468323693635/ 
Understanding-options-for-public-private-partnershipsin-infrastructure-sorting-out-the-forest-from-the-treesBOT-DBFO-DCMF-concession-lease.

4. Hammami M, Ruhashyankiko J F, Yehoue E B. Determinants of public-private partnership in infrastructure [Internet]. IMF working paper. Washington, DC: World Bank; 2006 [cited 2018 Oct 13]. 37 p. Available from: http://documents.worldbank. org/curated/en/936961468338942251/Determinants-ofpublic-private-partnerships-in-infrastructure.

5. Baliga B S, Ravikiran S R, Rao S S, Coutinho A, Jain A. Public-private partnership in health care: a comparative cross-sectional study of perceived quality of care among parents of children admitted in two government district-hospitals, Southern India. J Clin Diagn Res. 2016 Feb;10(2):SC05-SC09. doi: 10.7860/ JCDR/2016/17124.7250.

6. Hanefeld J, Powell-Jackson T, Balabanova D. Understanding and measuring quality of care: dealing with complexity. Bull World Health Organ. [Internet]. 2017 May 1;95(5):368-74. DOI: 10.2471/ BLT.16.179309 Available from: https://www.ncbi.nlm. nih.gov/pmc/articles/PMC5418826/.

7. Blaug M. The methodology of economics: or how economists explain. 2nd ed. Cambridge: Cambridge University Press; 1992. 286 p.

8. Ehrgott M. Vilfredo Pareto and multi-objective optimization. In Grötschel M, editor, Optimization stories: 21st International Symposium on Mathematical Programming, Berlin, Aug 19-24, 2012. Bielefeld. 2012. p. 447-453. (Documenta mathematica).

9. Reinhardt U E. Can efficiency in healthcare be left to the market? J Health Polit Policy Law. 2001 Nov;26(5):96792. DOI: 10.1215/03616878-26-5-967.

10. Kumar R, Chandrakar R, Kumar A, Ram Chandrakar H. Taguchi loss function as optimised model for supplier selection and evaluation. Int. J. Adv. Sci. Eng Inf Technol. 2012 Jan-Mar;III(I):268-70.

11. Taner T, Antony J. Applying Taguchi methods to health care. Int J Health Care Qual Assur Inc Leadersh Health Serv. 2006;19(1):xxvi-xxxv.

12. Yu K. Measuring efficiency and cost-effectiveness in the health care sector / K. Yu // Essays on the theory and practice of index numbers: the making of macroeconomics data. — Saarbrücken : VDM Verlag Dr. Müller, 2010. — 204 p.

\section{References.}

1. Saragiotis, P. (Ed.). (2009). Public-private partnerships in infrastructure days 2008. Washington, D.C., Dec 15-18 2008. Washington, D.C.: The International Bank for Reconstruction and Development/The World Bank.

2. Taylor, R. J. (2003). Contracting for health services In A. Harding, \& A. Preker (Eds.), Private Participation in Health Services. Health, Nutrition and Population (pp. 195-204). Washington, DC: The World Bank.
3. Delmon, J. J. (2010). Understanding options for publicprivate partnerships in infrastructure: sorting out the forest from the trees: BOT, DBFO, DCMF, concession, lease... Policy Research working paper, WPS 5173. Washington, DC: The World Bank.

4. Hammami, M., Ruhashyankiko, J. F., \& Yehoue, E B. (2006). Determinants of public-private partnership in infrastructure. IMF working paper. Washington, DC: World Bank.

5. Baliga, B. S., Ravikiran, S. R., Rao, S. S., Coutinho, A., \& Jain, A. (2016). Public-private partnership in health care: a comparative cross-sectional study of perceived quality of care among parents of children admitted in two government district-hospitals, Southern India. J. Clin. Diagn. Res., 10(2), SC05-SC09. doi: 10.7860/ JCDR/2016/17124.7250.

6. Hanefeld, J., Powell-Jackson, T., \& Balabanova, D. (2017). Understanding and measuring quality of care: dealing with complexity. Bull. World Health Organ., 95(5), 368-374. doi: 10.2471/BLT.16.179309.

7. Blaug, M. (1992). The methodology of economics: or how economists explain (2nd ed.). Cambridge: Cambridge University Press.

8. Ehrgott, M. (2012). Vilfredo Pareto and multi-objective optimization. In M. Grötschel (Ed.), Optimization stories: 21st International Symposium on Mathematical Programming, Berlin, Aug 19-24, 2012 (pp. 447-453). (Documenta mathematica; Vol. 2012). Bielefeld.

9. Reinhardt, U. E. (2001). Can efficiency in healthcare be left to the market? J. Health Polit. Policy Law, 26(5), 967-992. doi: 10.1215/03616878-26-5-967.

10. Kumar, R., Chandrakar, R., Kumar, A., \& Ram Chandrakar, H. (2012). Taguchi loss function as optimised model for supplier selection and evaluation. Int. J. Adv. Sci. Eng. Inf. Technol., III(I), 268-270.

11. Taner, T., \& Antony, J. (2006). Applying Taguchi methods to health care. Int. J. Health Care Qual. Assur. Inc. Leadersh. Health Serv., 19(1), xxvi-Xxxv.

12. Yu, K. (2010). Measuring efficiency and costeffectiveness in the health care sector. In K. Yu. Essays on the theory and practice of index numbers: the making of macroeconomics data (pp. 103-146). Saarbrücken: VDM Verlag Dr. Müller. 